Jähnig, Bernhart, Memel als Brücke zu den Baltischen Ländern. Kulturgeschichte Klaipedas vom Mittelalter bis ins 20. Jahrhundert

\title{
Mathieu Olivier
}

\section{(2) OpenEdition}

Édition électronique

URL : http://journals.openedition.org/ifha/6463

DOI : $10.4000 /$ ifha.6463

ISSN : 2198-8943

Éditeur

IFRA - Institut franco-allemand (sciences historiques et sociales)

Référence électronique

Mathieu Olivier, « Jähnig, Bernhart, Memel als Brücke zu den Baltischen Ländern. Kulturgeschichte Klaipédas vom Mittelalter bis ins 20. Jahrhundert », Revue de I'IFHA [En ligne], Date de recension, mis en ligne le 01 janvier 2012, consulté le 22 septembre 2020. URL : http://journals.openedition.org/ifha/ 6463 ; DOI : https://doi.org/10.4000/ifha.6463

Ce document a été généré automatiquement le 22 septembre 2020.

(C)IFHA 


\title{
Jähnig, Bernhart, Memel als Brücke zu den Baltischen Ländern. Kulturgeschichte Klaipédas vom Mittelalter bis ins 20. Jahrhundert
}

\author{
Mathieu Olivier
}

Le présent volume rassemble une partie des contributions présentées à l'été 2009 au colloque annuel de la Commission pour l'histoire de la Prusse Occidentale et Orientale, réuni pour l'occasion à Klaipÿda. Après un rapide avant-propos de la plume de B.J., le volume d'actes s'organise autour de trois temps aux titres pas forcément très évocateurs : "Moyen Âge et époque moderne ", " littérature et conscience de soi ", " problèmes politiques du Memelland ». Dans cet essai collectif « d'histoire culturelle de Memel », deux moments se taillent en réalité la part du lion : le Moyen Âge tardif - « l'ère teutonique » - et l'entre-deux-guerres. Plusieurs figures locales de quelque renom ont l'honneur d'une contribution, à commencer par l'écrivain Hermann Sudermann (I. Rinau) et le poète Fritz Kudnig (R. Knoll). Mais c'est bien l'histoire d'une ville et au-delà d'une petite région originale coincée entre Prusse, Lituanie et Courlande qui se trouve ici au centre de toutes les attentions. V. Žulkus et B.J., assurément les deux meilleurs connaisseurs actuels de la Memel médiévale, retracent respectivement les grandes étapes du développement urbain et la chronique des péripéties guerrières au temps de l'Ordre dans deux études successives et parfaitement complémentaires. Dans le droit fil de la perspective ouverte par le titre du volume, S. Hartmann s'essaie ensuite à préciser la fonction d'interface qui revint à la cité portuaire entre Livonie et Prusse ducale aux dernières heures de la présence teutonique dans la région. Après un tour d'horizon assez rapide des activités portuaires dans le dernier tiers du XVIIe siècle et les premières décennies du siècle suivant (A. Groth), le curseur se déplace vers le XXe siècle. La problématique des identités confessionnelles reçoit une attention particulière (A. Baublys, S. Pocyte), mais le dernier temps du volume s'attarde principalement sur quelques épisodes saillants de l'histoire mouvementée du Memelland de l'entre-deuxguerres (L. Oberdörfer, R. Shindo, D. Willoweit). On s'étonne que la principale 
contribution française à l'histoire du Memelland dans cette période cruciale soit ici passée sous silence : à savoir le travail d'Isabelle Chandavoine sur les années d'occupation française entre 1920 et 1932 (version remaniée et augmentée, en langue lituanienne : Prancūzmetis Klaipedoje ir kas po to 1920-1932 [= Klaipèda à l'heure française et après - 1920-1932], Vilnius, Žara, 2003).

Toutes les études réunies ici n'emportent pas au même degré la conviction du lecteur. Quelques-unes, inutilement longues, pèchent par verbosité. D'autres sont un peu difficiles d'accès pour un lecteur non lituanophone - on pense notamment aux considérations d'I. Rinau sur les traductions lituaniennes des œuvres d'Heinrich Sudermann. On ne s'en réjouira pas moins de voir Memel/Klaipėda et sa riche histoire remises au goût du jour par un panel international d'historiens et de linguistes de haut niveau ; la ville et sa région méritaient bien cet aggiornamento scientifique, au-delà ou à côté de la profuse Heimatliteratur de langue allemande et de publications touristiques plus ou moins bien informées. Il faut espérer que ce colloque soit une première pierre à l'édifice d'une nouvelle histoire générale de la ville, plus de cent ans après celle de Johannes Sembritzki.

Mathieu Olivier (lycée Dumont-d'Urville, Toulon) 